\title{
A High-Efficiency, High-Frequency Boost Converter using Enhancement Mode GaN DHFETs on Silicon
}

\author{
Jordi Everts*§, Jo Das ${ }^{\dagger}$, Jeroen Van den Keybus ${ }^{\ddagger}$, Jan Genoe ${ }^{\dagger \S}$, Marianne Germain ${ }^{\dagger}$ and Johan Driesen* \\ ${ }^{*}$ Kath. Universiteit Leuven (K.U.Leuven) \\ Dept. of Electrical Engineering ESAT-ELECTA \\ Kasteelpark Arenberg 10 \\ B-3001 Leuven, Belgium \\ Phone: +3216328620 , Fax: +3216321985 \\ jordi.everts@esat.kuleuven.be \\ ( ${ }_{\text {also at: KHLim, Diepenbeek, Belgium) }}$ \\ $\dagger$ IMEC Leuven \\ Kapeldreef 75 \\ B-3001 Leuven, Belgium \\ jdas@imec.be \\ ( ${ }_{\text {current address: }}$ \\ EpiGaN, Leuven, Belgium \\ Marianne.Germain@epigan.com) \\ ‡TRIPHASE \\ Romeinse Straat 18 \\ B-3001 Leuven, Belgium \\ jeroen.vandenkeybus@triphase.eu
}

Abstract-A boost converter was constructed using a high voltage enhancement mode (E-mode) AlGaN/GaN/AIGaN DHFET transistor grown on $\mathrm{Si}<111>$. The very low dynamic onresistance $\left(R_{d y n} \approx 0.23 \Omega\right)$ and very low gate-charges (e.g. $Q_{\text {gate }} \approx 15 \mathrm{nC}$ at $V_{D S}=200 \mathrm{~V}$ ) result in minor transistor losses. Together with a proper design of the passive components and the use of $\mathrm{SiC}$ diodes, very high overall efficiencies are reached. Measurements show high conversion efficiencies of 96.1\% $\left(P_{\text {out }}=106 \mathrm{~W}, 76\right.$ to $142 \mathrm{~V}$ at $\left.512.5 \mathrm{kHz}\right)$ and $93.9 \%$ $\left(P_{\text {out }}=97.5 \mathrm{~W}, 78\right.$ to $142 \mathrm{~V}$ at $\left.845.2 \mathrm{kHz}\right)$. These are, to our knowledge, the highest efficiencies reported for an enhancement mode GaN DHFET on $\mathrm{Si}$ in this frequency range. The transistor switching losses are concentrated in the turn-on interval, and dominate at high frequencies. This is due to a limited positive gate-voltage swing, as the gate-source diode restricts the positive drive voltage.

Index Terms-boost converter, enhancement mode (E-mode), GaN DHFET, high efficiency, very high frequency, wide bandgap

\section{INTRODUCTION}

GaN-based heterojunction field effect transistors (HFETs) are becoming of major interest as their outstanding properties make them a good replacement candidate for the currently used silicon devices in power electronic converters [1]. Their high electron mobility $\left(1000-2000 \mathrm{~cm}^{2} / \mathrm{Vs}\right)$, high breakdown voltage (3 MV/cm) and high power density make a further optimization of the energy conversion possible, resulting in an increase of efficiency and switching frequency compared to today's Si-based converters [2] - [3]. Moreover, these materials can be grown onto large diameter $\mathrm{Si}$ substrates, which is a major cost advantage, especially comparing to other widebandgap materials such as $\mathrm{SiC}$. The performance of $\mathrm{GaN}$ on-sapphire and GaN-on-SiC has already been demonstrated by $1 \mathrm{MHz}, 120$ and $300 \mathrm{~W}$ converters [2] - [3]. Nowadays more attention goes to enhancement mode (E-mode) GaN transistors due to the inherent safety [4] - [5]. In this paper, we show the performance of E-mode $\mathrm{AlGaN} / \mathrm{GaN} / \mathrm{AlGaN}$

This research is funded by a Ph.D grant of the Institute for the Promotion of Innovation through Science and Technology in Flanders (IWT-Vlaanderen). Jordi Everts is a doctoral research assistant of IWT-Vlaanderen. double-heterostructure FETs (DHFETs) [5], using a dedicated high-frequency boost-converter set-up. A hard switching boost topology is a good tool to demonstrate the advantages of GaN-based transistors in a power electronic converter as it is often used for power-factor-correction (PFC) front ends and as the basic building block of half bridges. As in today's SMPS design the trend is to move toward a more compact circuit design, the switching frequencies of interest approach the $\mathrm{MHz}$ range. First, the converter construction is discussed, including the design of the main power circuit, the gate drive circuit and the inductor. State-of-the art $\mathrm{SiC}$ diodes and an in-house developed planar inductor contribute to a more compact design and a highest possible efficiency. In a next section, the used GaN-based power transistors, being driven by dedicated drive circuitry are highlighted, including the device fabrication and device characterization. Finally, the overall converter performance is discussed. Attention goes to the results of several efficiency measurements, to the distribution of the converter losses as also to a possibility to improve the device and converter performance.

\section{CONVERTER CONSTRUCTION}

The design target was to construct a high-efficiency, highfrequency, hard switching boost converter wherein GaN-based DHFETs are used as switching devices. The frequency range of interest covers the $300 \mathrm{kHz}$ to $1 \mathrm{MHz}$ interval. The maximum convertible power mainly depends on the maximum allowed output voltage, being limited by the breakdown voltage of the used GaN switch to approximately $V_{B D}=200 \mathrm{~V}$ in this case. As a consequence, the results presented in this paper were obtained in a power range of 60 to $150 \mathrm{~W}$ output power. The main parts in the converter design are discussed in the next subsections. Special attention was paid to the design of the passive components and compactness of the converter, reducing the parasitic effects to a minimum and aiming for the highest possible efficiency. 


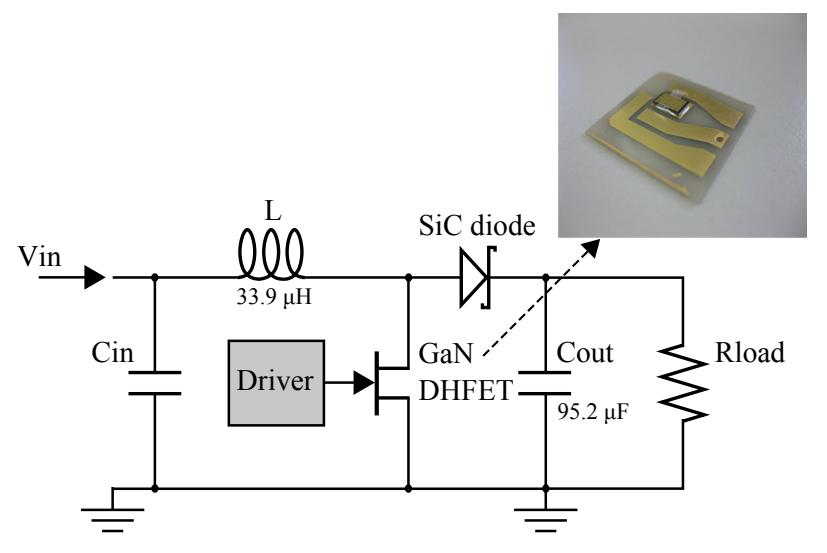

Fig. 1. Boost converter circuit with flexible high-frequency gate drive circuit (up to $2 \mathrm{MHz}$ ) to test the E-mode GaN DHFETs. (upper inset) GaN E-mode DHFET mounted on an AlN carrier substrate.

\section{A. Main power circuit}

Fig. 1 shows a diagram of the circuit under study. The main power circuit consists of an AlGaN/GaN/AlGaN E-mode DHFET power switch, a silicon carbide $(\mathrm{SiC})$ rectifying diode, an inductor (L), two filtration capacitors $\left(\mathrm{C}_{\text {in }}\right.$ and $\left.\mathrm{C}_{\text {out }}\right)$ and a load $\left(\mathrm{R}_{l o a d}\right)$. During the on-interval of the GaN switch, energy from the input line is stored in the inductor. As, for generality, only a duty cycle of around $50 \%$ is considered, this energy is then released to the load at twice the input voltage during the off-interval of the switch. The power circuit was built on a two-layer printed circuit board, being optimized for highfrequency switching (up to $1 \mathrm{MHz}$ ). Special attention was paid to the compactness of the converter, reducing parasitic effects. The rectifying diode is a $600 \mathrm{~V}$, zero recovery current SiC Schottky diode, providing superior switching characteristics which will lead to an increased efficiency, a reduced size and a higher possible switching frequency. The 4-A-rated C3D04060 diode from Cree Inc. showed the lowest sum of conduction and charging losses.

\section{B. Gate drive circuit}

The main requirement of the gate driver was the ability to deliver a gate-drive signal having a voltage range suitable to drive the E-mode GaN DHFET, at a frequency up to $1 \mathrm{MHz}$. In addition the fall and rise times of the gate signal had to be small in order to reach fast on and off switching. For meeting these requirements dedicated gate drive circuitry was developed [6]. A fully controllable gate-voltage range $\left(V_{G S}\right)$ was obtained at a switching frequency up to $6 \mathrm{MHz}$ :

$$
\begin{aligned}
& V_{G S, \text { on }}=V_{\text {range }}-V_{\text {off }} \\
& V_{G S, \text { off }}=0-V_{\text {off }}
\end{aligned}
$$

with

$V_{G S, \text { on }} \quad$ upper level of the gate-voltage range (V)

$V_{G S, o f f}$ lower level of the gate-voltage range (V)

$V_{\text {range }}$ gate-voltage range $\left(=V_{G S, o n}-V_{G S, o f f}\right)(\mathrm{V})$

$V_{\text {off }} \quad$ offset voltage, determining $V_{G S, \text { off }}(\mathrm{V})$
$V_{\text {range }}$ and $V_{\text {off }}$ are input voltages that can be applied to the gate drive circuit in order to set $V_{G S, o n}$ and $V_{G S, o f f}$. For example, to achieve a gate-voltage range of 1 to $-9 \mathrm{~V}, V_{\text {range }}$ and $V_{\text {off }}$ are respectively set to 10 and $9 \mathrm{~V}$. The upper level of the gate-voltage range is limited by the internal gate-source diode $\left(D_{\text {int }}\right)$ of the GaN DHFET to be at most $1.5 \mathrm{~V}$. The lower level of the gate-voltage range is preferably sufficiently negative in order to realize a fast turn-off switching of the transistor, since the threshold voltage of the E-mode $\mathrm{GaN}$ DHFET used for this study is only slightly above zero Volt.

\section{Magnetics: planar inductor}

The inductor used in the boost converter is an in-house developed planar inductor. This type of inductor allows for easy and fast assembly and offers the flexibility of tailoring the sizes and shapes of the individual turns. In addition, it is a more competitive and effective approach in terms of physical size reduction compared to the conventional type of inductor, keeping the converter design as compact as possible [7]. Fig. 2 depicts an exploded view of such a planar module, showing the planar ferrite cores together with the flat PCB windings. The specifications of the used planar inductor are listed in table I. Three E/PLT cores of the magnetic material 3F3 were used in combination with an air gap length $G=450 \mu \mathrm{m}$, providing a total inductance factor $A_{L}=3 \times 400=1200 \mathrm{nH}$. In combination with six copper turns on the $\mathrm{PCB}$, this results in a theoretical inductance of $L_{t h}=43.2 \mu \mathrm{H}$, being sufficient to keep the current ripple under control in the studied frequency range. The real inductance slightly differs from the theoretical one as in practice the air gap length is difficult to control precisely. The real inductance of the planar inductor was measured to be $L_{\text {meas }}=33.9 \mu \mathrm{H}$. This was done by evaluating the change of inductor current during the on-state of the transistor at a given input voltage $V_{i n}$. The inset of Fig. 5 shows an example of such an inductor current waveform. The physical volume of the inductor was calculated out of the core dimensions to be $V=19.3 \mathrm{~mm}^{3}$ with a surface $A=19.4 \mathrm{~mm}^{2}$ and a height $h=9.98 \mathrm{~mm}$.

TABLE I

PLANAR INDUCTOR: SPECIFICATIONS

\begin{tabular}{c|c}
\hline Core type & $3 \times$ E32/6/20-PLT32/20/3 \\
\hline Core material & $3 \mathrm{~F} 3$ \\
\hline Number of turns $(N)$ & 6 \\
\hline Gap length $(G)$ & $450 \mu \mathrm{m}$ \\
\hline Total inductance factor $\left(A_{L}\right)$ & $3 \times 400=1200 \mathrm{nH}$ \\
\hline Theoretical inductance $\left(L_{t h}\right)$ & $43.2 \mu \mathrm{H}$ \\
\hline Measured inductance $\left(L_{\text {meas }}\right)$ & $33.9 \mu \mathrm{H}$ \\
\hline Physical volume $(V)$ & $19.3 \mathrm{~mm}^{3}$ \\
\hline Surface $(A)$ & $19.4 \mathrm{~mm}^{2}$ \\
\hline Height $(h)$ & $\left.9.98 \mathrm{~mm}^{2}\right)$
\end{tabular}




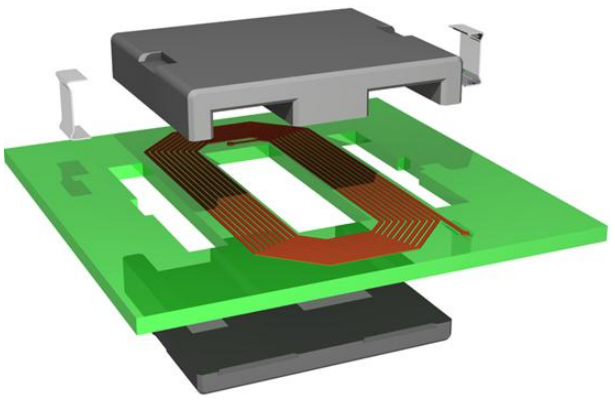

Fig. 2. Exploded view of a planar inductor, showing the planar ferrite cores and the flat PCB windings [8]

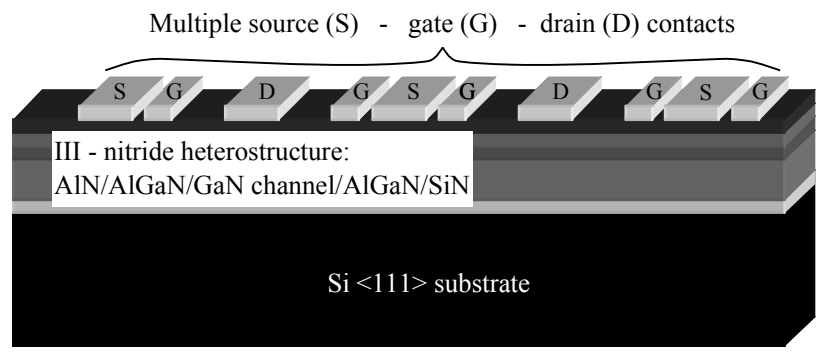

Fig. 3. Simplified cross-section of the GaN DHFET device. The power device is a lateral FET device, having multiple source (S) / gate (G) / drain (D) contacts on top of the III-nitride heterostructure.

\section{GAN ENHANCEMENT MOdE (E-MODE) DEVICES}

\section{A. Device fabrication}

The used transistors are large (total gate width $W_{G}=$ $57.6 \mathrm{~mm}$, gatelength $L_{G}=1.5 \mu \mathrm{m}$ ) enhancement mode (Emode) DHFETs, which are formed by parallelling smaller devices $\left(W_{G}=400 \mu \mathrm{m}\right)$ via an interconnection layer. These lateral power components are fabricated starting from a $\mathrm{Si}_{3} \mathrm{~N}_{4} / \mathrm{Al}_{45} \mathrm{Ga}_{55} \mathrm{~N} / \mathrm{GaN} / \mathrm{Al}_{18} \mathrm{Ga}_{82} \mathrm{~N}$ MOCVD grown heterostructure on a $\mathrm{Si}<111>$ substrate [9]. The in-situ grown $50 \mathrm{~nm} \mathrm{Si}{ }_{3} \mathrm{~N}_{4}$ layer caps the III-nitride heterostructure, passivating the surface and preventing strain relaxation of the $\mathrm{Al}_{45} \mathrm{Ga}_{55} \mathrm{~N}$ top layer [10]. In order to obtain an E-mode device, having a threshold voltage $V_{t h}>0$, the $\mathrm{Al}_{45} \mathrm{Ga}_{55} \mathrm{~N}$ barrier thickness is scaled down to a thickness below $5 \mathrm{~nm}$ and at the same time the in-situ grown $\mathrm{Si}_{3} \mathrm{~N}_{4}$ is selectively removed under the gate [5]. Fig. 3 shows a simplified crosssection of the GaN DHFET device.

\section{B. Device characterization}

On-wafer transfer characteristic measurements on the small devices (total gate width $W_{G}=200 \mu \mathrm{m}$, gatelength $L_{G}=$ $1.5 \mu \mathrm{m}$, and $4 \mathrm{~nm}$ top $\mathrm{Al}_{45} \mathrm{Ga}_{55} \mathrm{~N}$ layer) show a threshold voltage $V_{t h}=0.5 \mathrm{~V}$, an on-resistance $R_{\text {on }}=12 \Omega \cdot \mathrm{mm}$ and a maximum saturation current $I_{D S}=0.25 \mathrm{~A} / \mathrm{mm}$. An offstate breakdown voltage $V_{B D}$ of $600 \mathrm{~V}$ was obtained for a gate-drain gap $L_{G D}=8 \mu \mathrm{m}$ and an $\mathrm{Al}_{45} \mathrm{Ga}_{55} \mathrm{~N}$ buffer-layer thickness of $2 \mu \mathrm{m}$ [11].

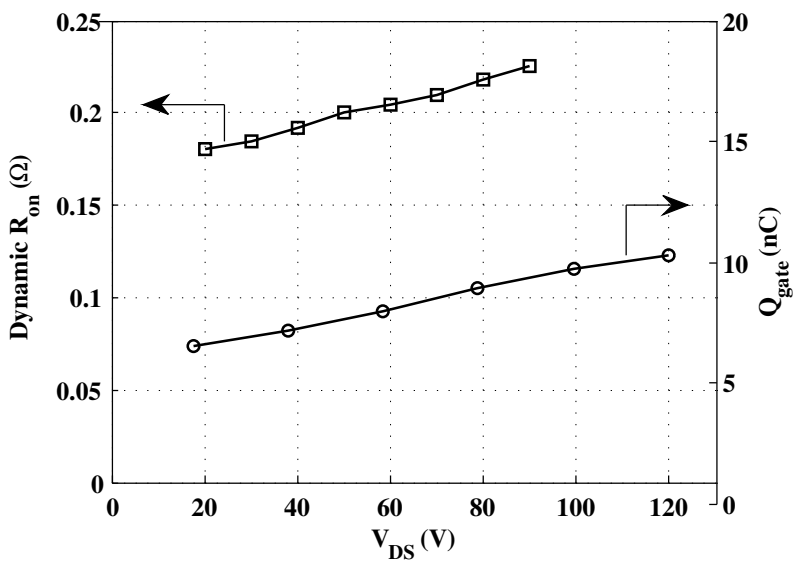

Fig. 4. Dynamic on-resistance $\left(R_{d y n}\right)$ and total gate charge $\left(Q_{\text {gate }}\right)$ of an E-mode GaN DHFET $\left(W_{G}=57.6 \mathrm{~mm}\right)$, measured using the boost converter shown in Fig. 1.

The large devices were characterized using the boost converter setup [12]. Fig. 4 shows the measured dynamic onresistance $\left(R_{d y n}\right)$ and total gate charge values $\left(Q_{\text {gate }}\right)$ of the GaN transistor. The dynamic on-resistance [13] is around $0.23 \Omega$ and only shows a very minor increase with increasing off-state drain voltage $\left(V_{D S, \text { off }}\right)$, proving the absence of the surface or bulk electron trapping in the device. A total gate charge value of $10 \mathrm{nC}$ is obtained at $V_{D S, \text { off }}=120 \mathrm{~V}$. These excellent properties result in low transistor losses (conduction respectively switching). To integrate the GaN DHFETs into power electronic circuits, the dies are packaged onto an AlN ceramic carrier (see inset of Fig. 1), acting as a heat spreader. Furthermore, the AlN carrier is mounted on an additional $\mathrm{Al}$ heat sink. A fan was used to force the convectional heat removal.

\section{PERFormanCE AND DISCUSSION}

\section{A. Efficiency measurements: results}

The performance of the converter was analyzed using a PM6000 Power Analyzer from Voltech. Input and output power are respectively measured through input channels I and II (see measurement setup in Fig. 5). For monitoring the waveforms of interest, a Tektronix oscilloscope was used in combination with a 1:100 voltage probe to measure voltages and with a differential probe to measure the inductor current via a shunt resistor $\left(R_{s h}=0.083 \Omega\right)$. Both the voltage probe and differential probe have a bandwidth of $500 \mathrm{MHz}$. The inset of Fig. 5 shows an example of the voltage and current waveforms respectively measured at the drain of the $\mathrm{GaN}$ switch and through the inductor when operating with 149.2 W output power at $710.6 \mathrm{kHz}$ switching frequency. Other operating parameters include a DC input voltage of $80.3 \mathrm{~V}$, a DC output voltage of $170 \mathrm{~V}$ and a duty cycle of around $50 \%$.

The converter was tested at several output voltages, frequencies and output power ranges, while keeping the duty cycle constant at approximately 50\%. Fig. 6 shows the efficiency 


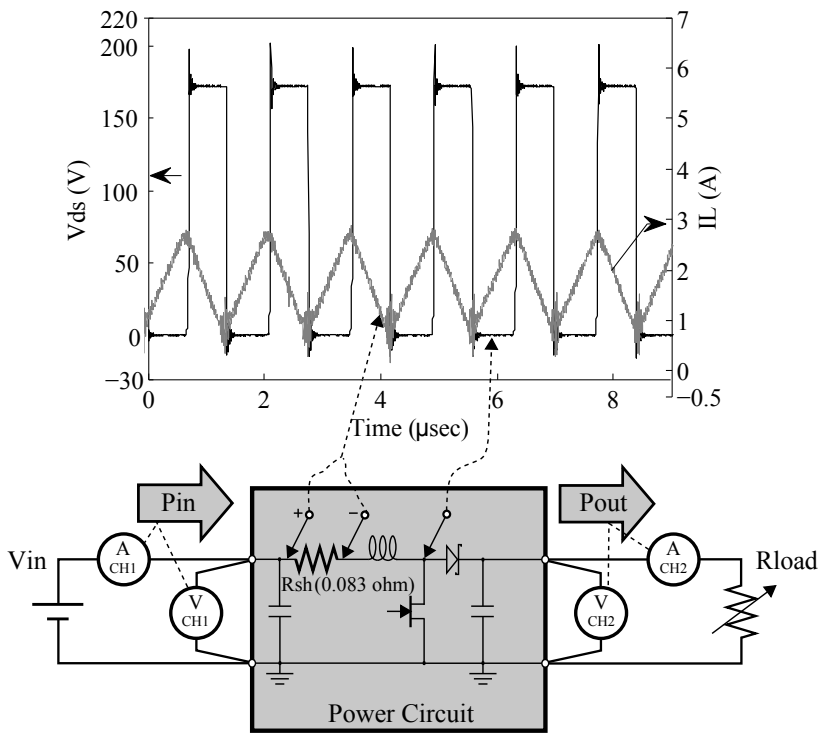

Fig. 5. Setup for measuring the input power, output power, inductor current and drain-voltage of the boost converter. (upper inset) Voltage and current waveforms, respectively measured at the drain of the $\mathrm{GaN}$ switch and through the inductor, showing hard-switched characteristics. Operating conditions include: $P_{\text {out }}=149.2 \mathrm{~W}, V_{\text {out }}=170 \mathrm{~V}, f=710.6 \mathrm{kHz}$ and $D=50 \%$.

measurements at $100 \mathrm{~W}$ output power for various output voltages in a frequency range from 303.8 to $845.2 \mathrm{kHz}$. The efficiency decreases, as expected, linearly with frequency. For an output voltage of $140 \mathrm{~V}$ the efficiency varies from $96.1 \%$ at $512.5 \mathrm{kHz}$ to $93.9 \%$ at $845.2 \mathrm{kHz}$. To our knowledge, these are the highest efficiencies reported for an enhancement mode GaN DHFET on a Si substrate in these operating conditions and frequency range [4]. The measured efficiencies include input filter, output filter and wiring losses. Losses in the shunt measurement resistor are excluded through the calculations. In theory, with the same power level, the conduction loss remains constant, whereas the switching loss linearly increases with switching frequency. However, at elevated switching frequencies, the slope of the total efficiency decrease in Fig. 6 becomes steeper, being an effect of increased eddy-current, proximity and hysteresis losses in the inductor as also of the reduced skin depth in the capacitor films. It can also be seen that the efficiency is higher at increased output voltages, as was expected. From Fig. 6 it is clear that when decreasing the frequency or working at higher voltages, even higher efficiencies can be reached. This is also illustrated by Fig. 7 where the conversion efficiency is shown for various switching frequencies in an output voltage range from 60 to $120 \mathrm{~V}$ at 0.85 A output current and $50 \%$ duty cycle.

\section{B. Distribution of the converter losses}

An evaluation of the converter losses was performed based on SPICE simulations in combination with a MATLAB calculation model using generic formulas. A SPICE model for the GaN DHFET was made before, starting from the DC and

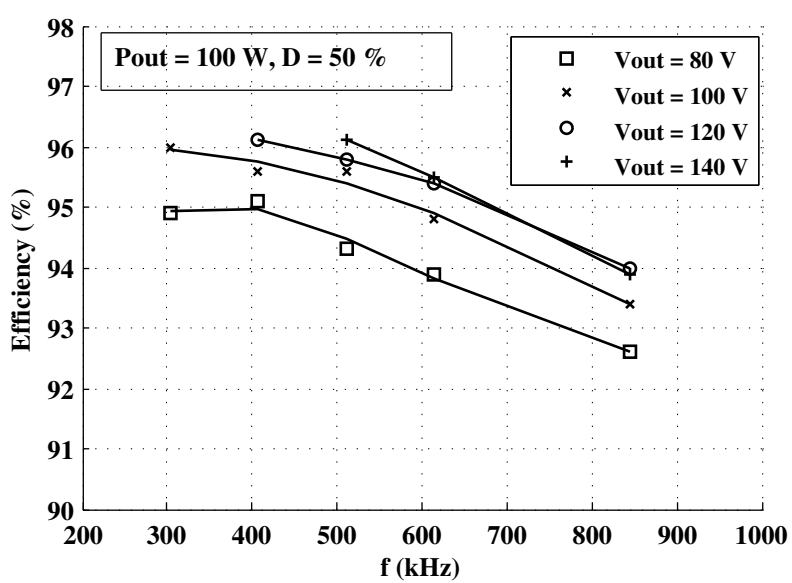

Fig. 6. Measured converter efficiency as a function of switching frequency, for various output voltages, at $100 \mathrm{~W}$ output power and $50 \%$ duty cycle.

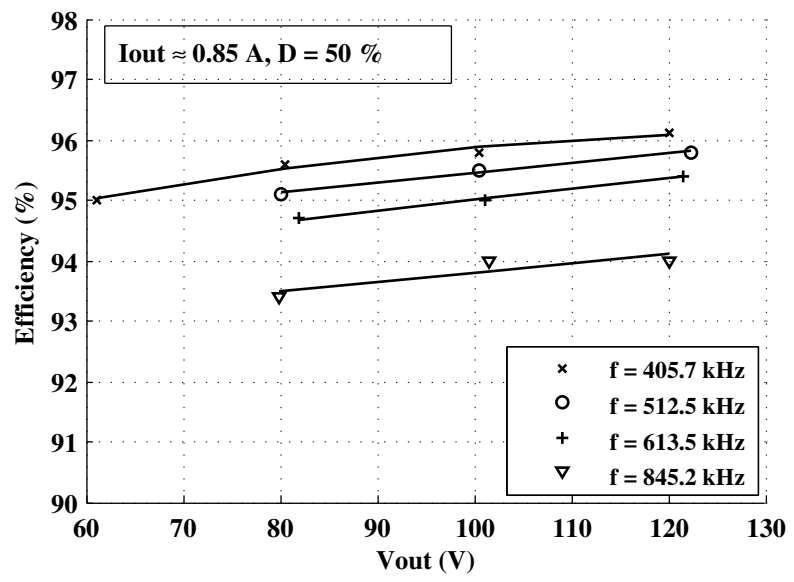

Fig. 7. Measured converter efficiency as a function of output voltage, for various switching frequencies, at $0.85 \mathrm{~A}$ output current and $50 \%$ duty cycle.

CV characterization of the devices [14]. Fig. 8 shows the distribution of the converter losses, expressed as percentage converter efficiency decrease, at $845.2 \mathrm{kHz}$ switching frequency, $142 \mathrm{~V}$ output voltage and $100 \mathrm{~W}$ output power. It can be seen that a major amount of the losses are switching related ( $2.7 \%$ efficiency decrease). Also the inductor has a substantial contribution to the overall converter losses, especially at this high frequency. The remarkable high turn-on loss of the $\mathrm{GaN}$ transistor is a result of a high fall time of the drainvoltage, finding its cause in the limited upper level of the gate-voltage range as explained in section II-B. Fig. 9 shows, for illustration, an example of the rise and fall flanks of the measured drain-voltage waveform at $179.5 \mathrm{~V}$ output voltage, $405.8 \mathrm{kHz}$ switching frequency and $50 \%$ duty cycle. The fall time $\left(t_{\text {fall }} \approx 26 \mathrm{~ns}\right)$ is much higher than the rise time $\left(t_{\text {rise }} \approx 5 \mathrm{~ns}\right)$. These numbers were read from the oscilloscope. One can also see that the measured waveforms are in very close agreement with the SPICE simulations. 


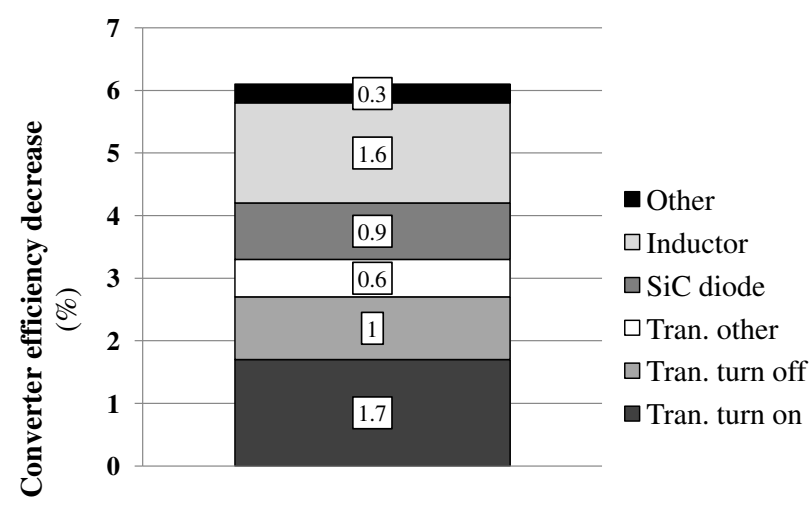

Fig. 8. Distribution of the converter losses at $P_{\text {out }}=100 \mathrm{~W}, V_{\text {out }}=142 \mathrm{~V}$, $f=845 \mathrm{kHz}$ and $D=50 \%$.
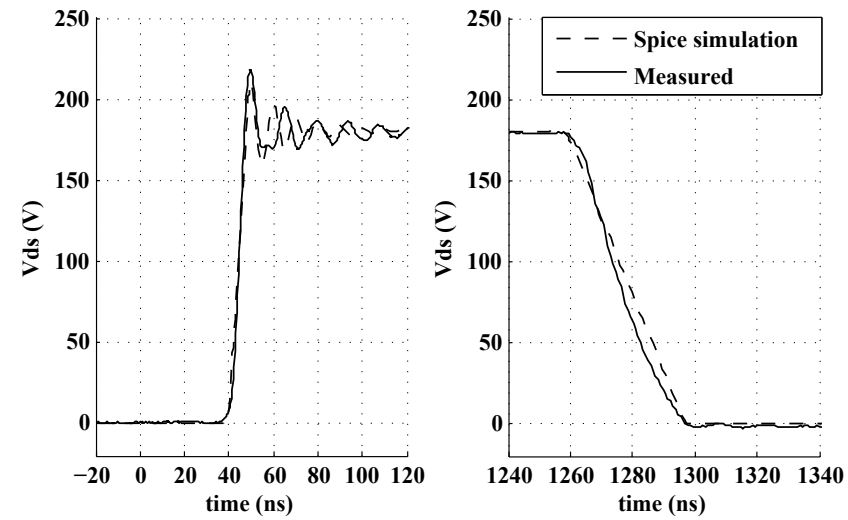

Fig. 9. Example of the rise and fall flanks of the measured drain-voltage waveform at $V_{\text {out }}=179.5 \mathrm{~V}, f=405.8 \mathrm{kHz}$ and $D=50 \%$. trise $_{\text {ris }} \approx 5 \mathrm{~ns}$ (left) and $t_{\text {fall }} \approx 26 \mathrm{~ns}$ (right).

\section{Improved on-switching: impact on the converter efficiency}

As the turn-on losses are one of the major contributors to the overall efficiency decrease, it is accountable to have a close look to their origin. According to the current and voltage profiles shown in Fig. 10, the switching losses can be described by the following equations:

$$
P_{S W}=P_{S W, o n}+P_{S W, o f f}
$$

where

$$
\begin{aligned}
& P_{S W, \text { on }}=\frac{I_{D} \cdot V_{D S, o f f}}{2} \cdot \frac{t_{2}+t_{3}}{T} \\
& P_{S W, \text { off }}=\frac{I_{D} \cdot V_{D S, o f f}}{2} \cdot \frac{t_{b}+t_{c}}{T}
\end{aligned}
$$

with

$P_{S W} \quad$ total switching loss $(\mathrm{W})$

$P_{S W, o n} \quad$ turn-on loss $(\mathrm{W})$

$P_{S W, \text { off }}$ turn-off loss (W)

$I_{D} \quad$ drain current (A)

$V_{D S, \text { off }} \quad$ off-state drain-source voltage (V)

$t_{2} \quad$ rise time of the drain current (ns)

$t_{3} \quad$ fall time of the drain voltage $=t_{\text {fall }}(\mathrm{ns})$

$t_{b} \quad$ rise time of the drain voltage $=t_{\text {rise }}(\mathrm{ns})$

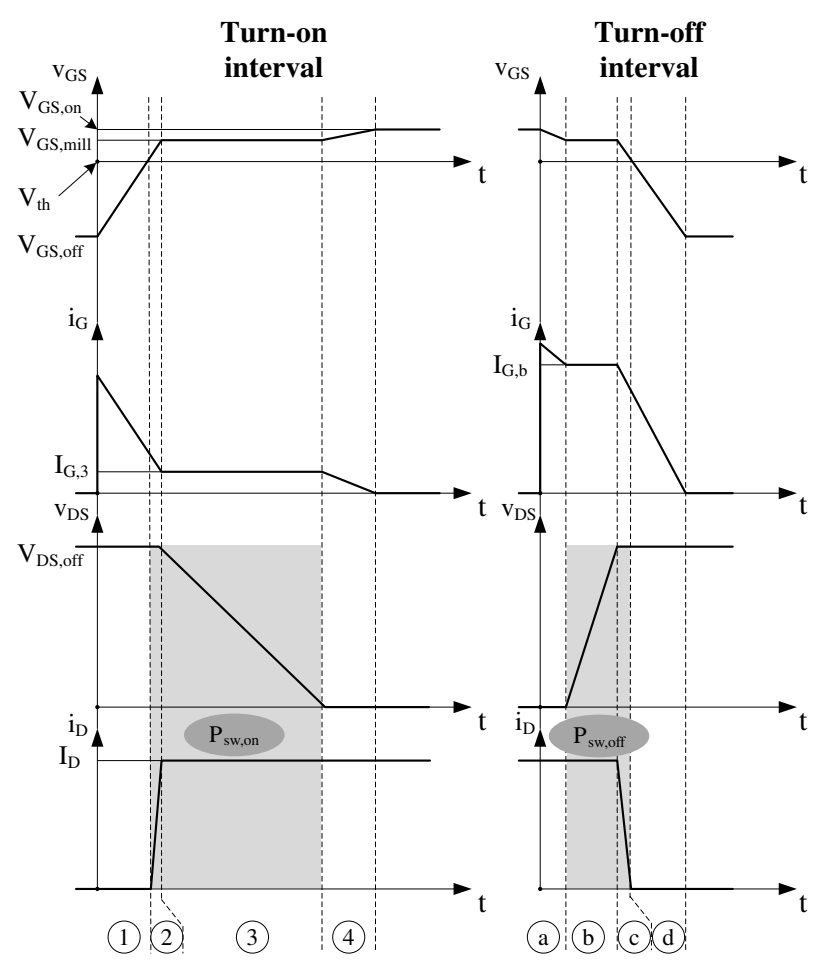

Fig. 10. GaN DHFET turn-on (left) and turn-off (right) intervals.

$t_{c} \quad$ fall time of the drain current (ns)

$v_{G S} \quad$ instantaneous gate-source voltage $(\mathrm{V})$

$V_{G S, \text { mill }}$ MILLER voltage (V)

$i_{G} \quad$ instantaneous gate current (A)

$I_{G, 3} \quad$ gate current during time interval 3 (A)

$I_{G, b} \quad$ gate current during time interval b (A)

$i_{D} \quad$ instantaneous drain current (A)

Most of the switching losses are situated in time intervals $t_{3}$ and $t_{b}$. During these intervals the gate-drain capacitance $\left(C_{r s s}\right)$ is charged/uncharged until a $V_{D S, o f f}$ voltage change across its terminals is reached. For the measurement shown in Fig. $9, t_{3}=t_{\text {fall }} \approx 26 \mathrm{~ns}$ and $t_{b}=t_{\text {rise }} \approx 5 \mathrm{~ns}$. According to the equations for charging/uncharging the capacitor $C_{r s s}$, the difference in fall $\left(t_{3}\right)$ and rise $\left(t_{b}\right)$ times is related to the gate-current $\left(I_{G}\right)$ in these intervals:

$$
t_{3}=C_{r s s} \cdot \frac{V_{D S, o f f}}{I_{G, 3}} \quad t_{b}=C_{r s s} \cdot \frac{V_{D S, o f f}}{I_{G, b}} \quad C_{r r s}=C_{G D}
$$

Hereby, $I_{G}$ is constant during each interval $\left(t_{3}\right.$ and $\left.t_{b}\right)$ and is determined by:

$$
I_{G}=\frac{V_{A-B}}{R_{G, t o t}} \quad V_{G S, \text { mill }} \approx 0 \mathrm{~V}
$$

with

$$
\begin{aligned}
& V_{A-B, t 3}=V_{G S, \text { on }}-V_{G S, \text { mill }} \\
& R_{G, t o t}=R_{d r, h i}+R_{G}+R_{G, i}
\end{aligned}
$$




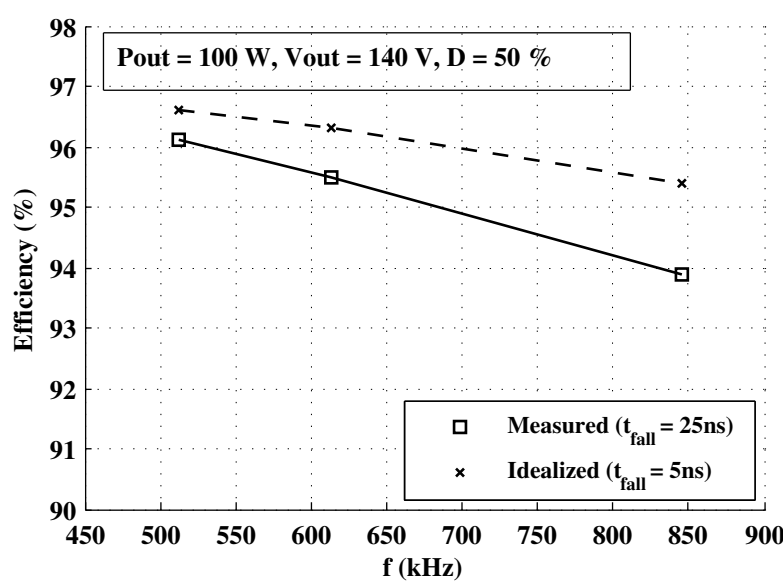

Fig. 11. Idealized efficiency assuming $t_{\text {fall }}$ to be as small as $t_{\text {rise }} \approx 5 \mathrm{~ns}$. $V_{\text {out }}=140 \mathrm{~V}, P_{\text {out }}=100 \mathrm{~W}$.

and

$$
\begin{aligned}
& \left|V_{A-B, t b}\right|=\left|V_{G S, \text { off }}\right|+V_{G S, \text { mill }} \\
& R_{G, \text { tot }}=R_{d r, l o}+R_{G}+R_{G, i}
\end{aligned}
$$

$V_{A-B} \quad$ driving voltage $(\mathrm{V})$

$R_{G, t o t}$ total gate resistance $(\Omega)$

$R_{d r, h i}$ internal high level output resistance of the driver $(\Omega)$

$R_{d r, l o}$ internal low level output resistance of the driver $(\Omega)$

$R_{G} \quad$ external gate resistance $(\Omega)$

$R_{G, i} \quad$ internal gate resistance of the GaN DHFET $(\Omega)$

$V_{G S, \text { on }}$ is limited by the internal gate-source diode $D_{\text {int }}$ of the GaN DHFET. This means that the driving voltage $V_{A-B, t 3}$ during $t_{3}$ is limited to only $1.5 \mathrm{~V}$. In contrast, $V_{G S, \text { off }}$ is not limited and was chosen to be $\approx-9 \mathrm{~V}$, resulting in a bigger driving voltage $V_{A-B, t b}$ during $t_{b}$ of $9 \mathrm{~V}$. This explains that $t_{3} \gg t_{b}$. We conclude that in order to decrease the turn-on time, the positive gate-voltage swing needs to be increased. This can be realized by replacing the Schottky gate by a MOS gate. Fig. 11 shows for an output voltage of $140 \mathrm{~V}$ and an output power of $100 \mathrm{~W}$ what the efficiency would be if assuming that $t_{\text {fall }}$ would be as small as $t_{\text {rise }} \approx 5 \mathrm{~ns}$. Now the efficiency varies from $96.6 \%$ at $512.5 \mathrm{kHz}$ to $95.4 \%$ at $845.2 \mathrm{kHz}$ instead of 96.1 respectively $93.9 \%$. Fig. 12 compares the new distribution of the converter losses with the one already mentioned in Fig. 8. The efficiency increase is around $1.5 \%$.

\section{CONCLUSION}

A high-frequency, hard-switching boost converter was constructed to test E-mode AlGaN/GaN/AlGaN doubleheterostructure FETs and to investigate their benefit concerning converter efficiency and circuit compactness. The low dynamic on-resistance and low gate charges of the components result in low transistor losses, enabling very high switching frequencies and a compact converter design. A high power

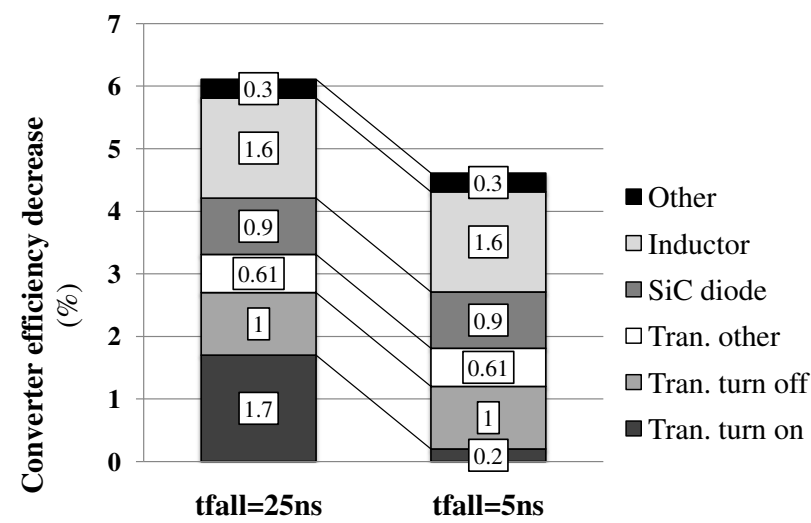

Fig. 12. Distribution of the converter losses at $P_{\text {out }}=100 \mathrm{~W}, V_{\text {out }}=$ $142 \mathrm{~V}, f=845 \mathrm{kHz}$ and $D=50 \%$.

efficiency of 93.9 to $96.1 \%$ was reached in the $512-845 \mathrm{kHz}$ frequency range at $100 \mathrm{~W}$ output power and $140 \mathrm{~V}$ output voltage. These are, to our knowledge, the highest efficiencies reported for an E-mode GaN DHFET on Si in this frequency range. Allowing higher positive gate drive voltages would increase these efficiencies to 95.4 respectively $96.6 \%$. By analyzing the power loss distribution in the converter, it was seen that a major amount of the losses are switching related. Also the passives substantially contribute to the overall converter losses, especially at higher frequencies. The optimization of these components, as well as driving the devices at higher gate voltages does offer a clear roadmap to even higher converter efficiencies.

\section{FUTURE WORK}

Future work includes an optimization of the planar inductor. Crucial in the design of the inductor is the air-gap position as also the right choice of the core material. New core materials (3F45) have been developed and will be considered in the near future. A comparison with commercially available $\mathrm{GaN}$ devices (e.g. EPC) belongs also to the future roadmap.

\section{REFERENCES}

[1] L. F. Eastman and U. K. Mishra, "The toughest transistor yet," IEEE Spectr., vol. 39, no. 5, pp. 28-33, May 2002.

[2] W. Yifeng, M. Jacob-Mitos, M. L. Moore, and S. Heikman, "A 97.8\% efficient GaN HEMT boost converter with $300-\mathrm{W}$ output power at 1 MHz,' IEEE Electron Device Letters, vol. 29, no. 8, pp. 824-826, Aug. 2008 .

[3] W. Saito, T. Nitta, Y. Kakiuchi, Y. Saito, K. Tsuda, I. Omura, and M. Yamaguchi, "A 120-W boost converter operation using a high-voltage GaN-HEMT," IEEE Electron Device Letters, vol. 29, no. 1, pp. 8-10, Jan. 2008.

[4] K. Boutros, S. Burnham, D. Wong, K. Shinohara, B. Hughes, D. Zehnder, and C. McGuire, "Normally-off 5A/1100V GaN-on-silicon device for high voltage applications," in IEEE Intern. Electron Devices Meeting (IEDM 2009), Baltimore, USA, Dec. 2009.

[5] J. Derluyn, M. Van Hove, D. Visalli, A. Lorenz, D. Marcon, P. Srivastava, K. Geens, B. Sijmus, J. Viaene, X. Kang, J. Das, F. Medjdoub, K. Cheng, S. Degroote, M. Leys, G. Borghs, and M. Germain, "Low leakage high breakdown E-mode GaN DHFET on $\mathrm{Si}$ by selective removal of in-situ grown $\mathrm{Si}_{3} \mathrm{~N}_{4}$," in IEEE Intern. Electron Devices Meeting (IEDM 2009), Baltimore, USA, Dec. 2009. 
[6] P. Jacqmaer, J. Everts, R. Gelagaev, P. Tant, and J. Driesen, "Fast robust gate-drivers with easy adjustable voltage ranges for driving normallyon wide-bandgap power transistors," in International Power Electronics and Motion Control Conference (EPE-PEMC 2010), Ohrid, Macedonia, Sep. 2010.

[7] A. I. Maswood and L. K. Song, "Design aspects of planar and conventional SMPS transformer: a cost benefit analysis," IEEE Trans. on Industrial Electronics, vol. 50, no. 3, 2003.

[8] A planar inductor. [Online]. Available: http://www.answers.com/topic/magnetic-core

[9] K. Cheng, M. Leys, J. Derluyn, K. Balachander, S. Degroote, M. Germain, and G. Borghs, "AlGaN-based heterostructures grown on 4 inch $\mathrm{Si}<111>$ by MOVPE," Phys. Stat. Sol.(c), vol. 5, no. 6, pp. 1600-1602, May 2008.

[10] J. Derluyn, S. Boeykens, K. Cheng, R. Vandersmissen, J. Das, W. Ruythooren, S. Degroote, M. R. Leys, M. Germain, and G. Borghs, "Improvement of $\mathrm{AlGaN} / \mathrm{GaN}$ high electron mobility transistor structures by in-situ deposition of a $\mathrm{Si}_{3} \mathrm{~N}_{4}$ surface layer," J. Appl. Phys., vol. 98, no. 5, p. 054501, Sep. 2005.

[11] D. Visalli, M. Van Hove, J. Derluyn, S. Degroote, M. Leys, K. Cheng, M. Germain, and G. Borghs, "AlGaN/GaN/AlGaN double heterostructures on silicon substrates for high breakdown voltage field-effect transistors with low on-resistance," Jpn. J. Appl. Phys, vol. 48, p. 04C101, Apr. 2009.

[12] J. Everts, P. Jacqmaer, R. Gelagaev, J. Van den Keybus, J. Das, M. Germain, and J. Driesen, "A hard switching VIENNA boost converter for characterization of AlGaN/GaN/AlGaN power DHFETs," in International Exhibition and Conference for Power Electronics Intelligent Motion Power Quality (PCIM2010), Nuremberg, Germany, May 2010.

[13] W. Saito, T. Nitta, Y. Kakiuchi, Y. Saito, K. Tsuda, I. Omura, and M. Yamaguchi, "Suppression of dynamic on-resistance increase and gate charge measurements in high-voltage GaN-HEMTs with optimized fieldplate structure," IEEE Trans. on Electron Devices, vol. 54, no. 8, Aug. 2007.

[14] J. Das, D. Marcon, M. Van Hove, J. Derluyn, M. Germain, and G. Borghs, "Switching assessment of GaN transistors for power conversion applications," in Proc. $13^{t} h$ European Conference on Power Electronics and Applications (EPE 2009), Barcelona, Spain, Sep. 2009. 